Fifth International Conference on Sustainable Construction Materials and

Technologies. http://www.claisse.info/Proceedings.htm

\title{
MECHANICAL PROPERTIES, SHRINKAGE, ABRASION RESISTANCE AND CARBONATION OF CONCRETE CONTAINING RECYCLED COARSE AGGREGATE OF DIFFERENT SIZE RANGE
}

\author{
Rakesh Kumar, Ph.D. \\ Senior Principal Scientist \& Head, Rigid Pavement Division, \\ CSIR-Central Road Research Institute \\ Delhi - Mathura Road, New Delhi-110025, INDIA. \\ Email: rakeshkumar.crrii@nic.in
}

\begin{abstract}
The coarse aggregate component in concrete ranges from $35 \%$ to $55 \%$ of the total mass, therefore; the characteristics of coarse aggregate significantly influence properties of a concrete. The presence of different components in recycled coarse aggregate obtained from recycling of construction and demolition waste makes the aggregate properties dynamic in nature compared with a natural crushed aggregate. This paper discusses influence of replacement of natural aggregate of size range $4.75-20 \mathrm{~mm}$ by recycled concrete aggregate (RCA) on mechanical properties, drying shrinkage, abrasion resistance, and carbonation of concrete. The study on mechanical properties of concrete suggests that $50 \%$ replacement of natural aggregate in size range $10-20 \mathrm{~mm}$ by RCA has insignificant influence on compressive and flexural strength of concrete. However, the abrasion resistance, drying shrinkage, and carbonation durability of such concrete are inferior to the control concrete yet adequate for several applications including the construction of cement concrete roads for pneumatic tired traffic.
\end{abstract}

Keywords: Recycled coarse aggregate, abrasion resistance, carbonation, concrete, shrinkage, compressive strength, flexural strength

\section{INTRODUCTION}

Though aggregate demand is entirely based upon region to region, its availability is becoming scarce. The world aggregate demand is about 50 billion tones [Yanik 2016]. This staggering demand of aggregates calls for finding out suitable 
alternate sources. Considering economic prospective as one of the agenda and sustainability as the main goal, the aggregate obtained from recycling of concretized portion of construction and demolition waste (CDW), has a very promising option due to its wide availability [Naik and Kumar 2015, Mahta 2001]. The construction and demolition is may be considered as a continuous process and the world needs to address the management of solid waste generated from such activities. Use of recycled concrete aggregate is feasible, especially where a good source of aggregate is scarce and disposal cost is high. RCA can be used as an aggregate in cement as well as in asphaltic concrete mixes [Mabin 1993]. Since, RCA is derived from concreted rubble of CDW, it contains other deleterious material which restricts it from being a substitute of a good quality natural aggregate. Many researchers [Ravindrajah and Tam 1985; Buck 1997; Katz 2003; Kumar 2017; Salem et al. 2003; Poon et al. 2004; Debib et al. 2010; Chen et al. 2003] have concluded that mortar attached to the recycled aggregate has lower density, higher water absorption, higher porosity and lower specific gravity than virgin aggregate hence, its use cause a decrease in both mechanical strength and durability of concrete [Xiao et al. 2005; Knack and Kurama 2013; Kumar and Shekhawat 2016; Poon et al 2004a; Tavakoli and Soroushin 1996; Domingo-cabo et al. 2009]. The durability issue is due to the porosity which is being rendered by mortar attached to the RCA [Ann et al. 2008]. Since, the concrete made up of recycled aggregate consists of two interfacial transition zones (ITZs), (One between recycled aggregate and mortar attached to it and other between recycled aggregate and new cement matrix). The reason behind reduced mechanical performance is the 'weak link' of the interfacial region between recycled aggregate and cement mortar attached to it. The mortar attached to the aggregate contains many micro pores and cracks which when exposed to water during mixing, absorbs much water which ultimately results in deficiency of water for hydration at the ITZ of concrete made with RCA [Otsuki et al. 2003, Levy and Helene 2004]. Therefore, at macro level, the increased porosity makes RCA more permeable to ions which limits RCA use in structural purposes especially in reinforced cement concrete (RCC) [Xuequan et al. 1987]. However, it is important to note that the quality of the concrete made with RCA entirely depends upon its quality, the level of replacement of natural aggregate, the amount of mortar adhered to it, and other similar factors. Due to a wide variation in the available literature, it is apparent that numerous experimental data be generated for in-house needs, using local RCA, in order to draw any specific conclusion for a given project activity. This paper presents the influences of replacement of natural coarse aggregate by RCA in size range 4.75-10, 10-20 \&4.75-20 $\mathrm{mm}$ on mechanical, drying shrinkage, abrasion and carbonation properties of concrete.

\section{EXPERIMENTAL PROGRAM}

\section{Materials}

The materials used included an ordinary Portland cement meeting having specific gravity of 3.12, a crushed quartzite natural coarse aggregate (NCA) and a recycled concrete aggregate (RCA) with gradation as shown in Table 1 and physical properties as given in Table 2, a land quarried sand having water absorption, specific gravity, and bulk density of $1.0 \%, 2.65$, and $1600 \mathrm{~kg} / \mathrm{m}^{3}$, respectively. A high range water reducing agent was used as super plasticizer. Potable water was used for mixing and curing of concrete specimens. 
Table 1. Gradation of NCA and RCA

\begin{tabular}{lllll}
\hline Sieve size $(\mathrm{mm})$ & \multicolumn{2}{c}{ \% passing, $20 \mathrm{~mm}$ msa } & \multicolumn{2}{c}{ \% passing, $10 \mathrm{~mm}$ msa } \\
& NCA & RCA & NCA & RCA \\
\hline 25 & 100 & 100 & -- & -- \\
20 & 91 & 91.5 & -- & - \\
12.5 & 19.6 & 17.6 & 100 & 100 \\
10 & 2.3 & 3 & 85.3 & 90 \\
4.75 & 0.7 & 0.4 & 3.8 & 27.4 \\
2.36 & -- & -- & 0.11 & 9.1 \\
\hline
\end{tabular}

Table 2. Physical properties of RCA and NCA

\begin{tabular}{lcc}
\hline Physical properties & RCA & NCA \\
\hline Specific gravity & $2.24,2.45$ & 2.71 \\
Aggregate crushing value, $\%$ & $23.8-30.7$ & $20.2-28.17$ \\
Bulk density, kg/m ${ }^{3}$ & $1470-1520$ & $1570-1650$ \\
Water absorption, \% & $4.23(10-20 \mathrm{~mm})$ & 0.48 \\
Water absorption, \% & $6.8(4.75-10 \mathrm{~mm})$ & 0.74 \\
Soundness (by Sodium & 16.17 & 4.97 \\
sulphate solution), \% & $18.5-21.1$ & 12.4 \\
Wet aggregate impact value, & & \\
(WAIV), \% & $30.2-33.8$ & $21.3-21.6$ \\
LA abrasion, $\%$ & & \\
\hline
\end{tabular}

\section{Properties of RCA and natural crushed aggregate (NCA)}

The RCA of the nominal maximum size range of 4.75-10 $\mathrm{mm}$ and 10-20 $\mathrm{mm}$ were collected from a commercial recycling plant from time to time in order to assess variation in its composition, physical and mechanical properties. The natural crushed quartzite aggregate of the same size range was used for the comparison of the properties of the RCA. The RCA was inhomogeneous, unlike natural crushed aggregate; hence it was evaluated thoroughly for its compositions and other physical properties. The composition of RCA was evaluated by determining the presence of different materials in it. The average value obtained from three samples for different constituents of RCA by mass and water absorption by them are presented in Table 3. The same exercise was not done for RCA in size range $4.75-10 \mathrm{~mm}$. The gradation of RCA was very similar to the gradation of the crushed natural aggregate for the size range $10-20 \mathrm{~mm}$ but it was about $27 \%$ finer than $4.75 \mathrm{~mm}$ for the aggregate of size range $4.75-10 \mathrm{~mm}$ (Table 1). Therefore, the coarse aggregate of this size range was used only after screening it through a 5 $\mathrm{mm}$ size wire mesh. Proper determination of water absorption by RCA is very important due to its dynamic nature.

The different constituents present in RCA make it difficult to restrict the water absorption within the permissible limit of $2 \%$ as prescribed in Indian Standard IS: 456, 2010 [23]. The smaller size range of RCA has a higher value for water absorption than larger size range of RCA (Table 2). As shown in Table 2, the mass loss of RCA in the soundness test is more than three folds of natural aggregate. In general, the properties of RCA are inferior to natural crushed aggregate.

Table 3. Components and water absorption of RCA of size 10-20 mm

\begin{tabular}{lll}
\hline Components & $\%$ by mass & Water absorption $\%$ \\
\hline
\end{tabular}




\begin{tabular}{lll}
\hline Sand stone (Red) & 3.1 & Negligible \\
Mable & 0.4 & Negligible \\
$\begin{array}{l}\text { Aggregate adhered } \\
\text { mortar }\end{array}$ & 5.5 & 7.6 \\
Brick & & \\
Concrete aggregate & 0.4 & 14.7 \\
Cement Mortar & 85.9 & 0.29 \\
\hline
\end{tabular}

\section{Mix Proportions}

Initially, four concrete mixes namely; a controlled (without RCA, M1), 50\% replacement of the natural aggregate (NCA) in the size range of 10-20 mm (M2), $100 \%$ replacement of NCA by RCA of size range 10-20 mm (M3), and $100 \%$ replacement of complete natural coarse aggregate by RCA (in size range 4.75-20 $\mathrm{mm}$ ) (M4) were used to study the influences of RCA on properties of concrete. Additionally, two more concrete mixes (M5 and M6) were also prepared at a higher w/c ratio than mixes M1, M2, M3, and M4. The NCA was replaced by RCA on mass to mass basis. The higher water absorption by RCA was accounted for in mixes by the addition of extra water needed to bring RCA in SSD condition. The free water-to-cement ratio for mixes M1, M2,M3 and M4 was kept 0.38, while the same for mixes M5 and M6 was 0.44. The Mix 1 was targeted for a 28day compressive strength of $45 \mathrm{MPa}$. The details of mix proportions are given in Table 4.

Table 4. Detail of concrete mixes $\left(\mathrm{kg} / \mathrm{m}^{3}\right)$

\begin{tabular}{|c|c|c|c|c|c|c|c|c|c|}
\hline \multirow[t]{2}{*}{ Mix } & \multirow{2}{*}{$\begin{array}{l}\text { Cement } \\
(\mathrm{kg})\end{array}$} & \multirow{2}{*}{$\begin{array}{l}\text { Water } \\
(\mathrm{kg})\end{array}$} & \multirow{2}{*}{$\begin{array}{l}\text { Sand } \\
(\mathrm{kg})\end{array}$} & \multicolumn{2}{|c|}{ NCA (kg) } & \multicolumn{2}{|c|}{ RCA (kg) } & \multirow{2}{*}{$\begin{array}{l}\text { Slump } \\
(\mathrm{mm})\end{array}$} & \multirow{2}{*}{$\begin{array}{l}\text { Fresh } \\
\text { density } \\
\mathrm{kg} / \mathrm{m} 3\end{array}$} \\
\hline & & & & $\begin{array}{l}10- \\
20 \\
(\mathrm{~mm})\end{array}$ & $\begin{array}{l}4.75- \\
10 \\
(\mathrm{~mm})\end{array}$ & $\begin{array}{l}10- \\
20 \\
(\mathrm{~mm})\end{array}$ & $\begin{array}{l}4.75- \\
10 \\
(\mathrm{~mm})\end{array}$ & & \\
\hline M1 & 390 & 150 & 750 & 696 & 464 & 0 & 0 & 40 & 2445 \\
\hline M2 & 390 & 150 & 750 & 348 & 464 & 348 & 0 & 35 & 2420 \\
\hline M3 & 390 & 150 & 750 & 0 & 464 & 696 & 0 & 25 & 2390 \\
\hline M4 & 390 & 150 & 750 & 0 & 0 & 696 & 464 & 25 & 2350 \\
\hline M5 & 330 & 144 & 695 & 760 & 506 & 0 & 0 & 50 & 2430 \\
\hline M6 & 330 & 144 & 695 & 0 & 0 & 760 & 506 & 30 & 2370 \\
\hline
\end{tabular}

\section{EXPERIMENTAL INVESTIGATION}

\section{Mixing and Specimens Preparation}

Mixing and subsequent concrete specimen's preparation was done as per standard procedure. The mixing time was kept more than the conventional one to allow adequate water to be got absorbed by RCA. The standard specimens were cast for the evaluation of concrete properties.

\section{Replacement Influence of NCA by RCA on Concrete Properties}

\section{Slump and Fresh Density of Concrete}

The influence of replacement of NCA by RCA was investigated on slump and fresh density of concrete. The density was determined by just dividing the mass of the concrete filled and compacted in a container of the known volume. Table 4 presents the slump and fresh density of the concrete mixes. 


\section{Mechanical Properties of Concrete}

The compressive and flexural strengths were evaluated as mechanical properties of concrete to know the influences of replacement of NCA by RCA. Standard specimens were used to determine the compressive, flexural strengths, carbonation depth, abrasion resistance and shrinkage properties of concrete. These specimens were demolded after 24 hours of casting and curing in steel mould. Then, these specimens were stored in curing tanks at room temperature $\left(27^{\circ} \pm 2^{\circ} \mathrm{C}\right)$ till the age of testing.

\section{Drying Shrinkage}

Drying shrinkage test was carried out at the age of 28 days as per ASTM -C596. The beams were removed from the curing tank at the age of 28 days and their initial length was measured using a length comparator device. The specimens were subjected to several cycles of drying (44-hr), cooling (4-hr) before the length measurement. This process was continued till a constant length was attained, or the difference between the two consecutive readings became less than $0.02 \mathrm{~mm}$. The drying shrinkage was calculated as the difference of lengths expressed as the percentage of the original length of the specimen.

\section{Abrasion Resistance}

Abrasion loss of concrete was determined by sand blasting method as per IS: 9284-1979. The abrasion loss of specimen was taken as the loss in mass in gram for two separate impressions on the same face of cube under test. Fig. 1 shows a cube specimen before and after the abrasion testing.

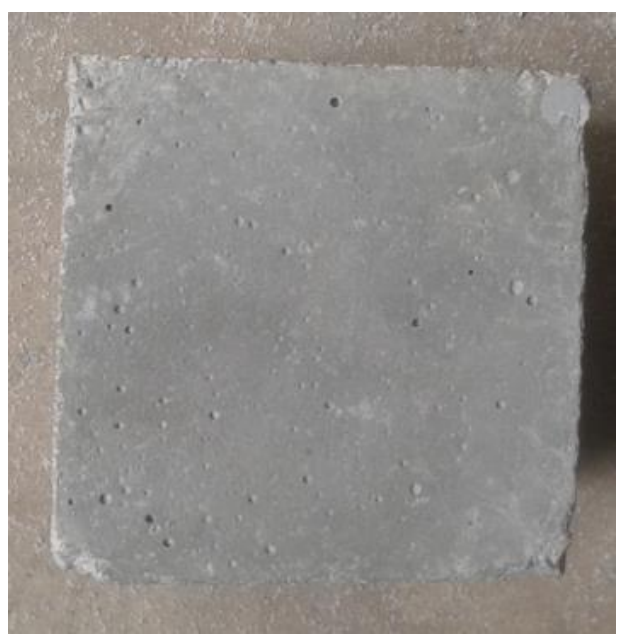

(a) Before test

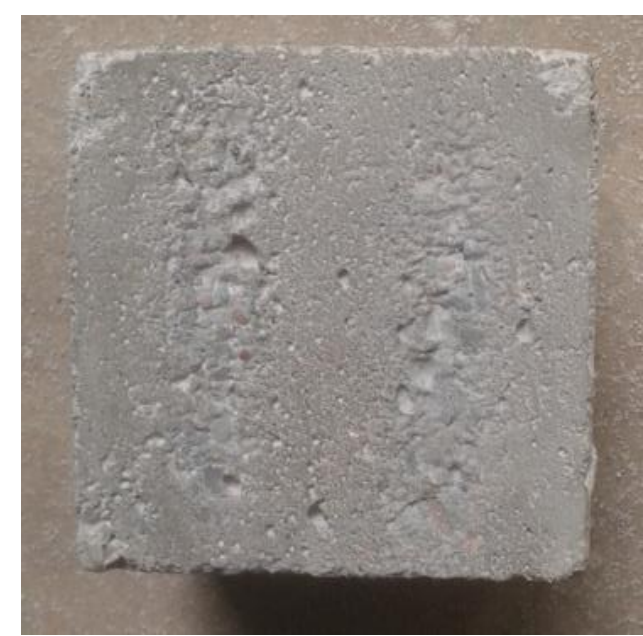

(b) After abrasion test

Fig.1: Cube before and after abrasion testing.

\section{Carbonation Depth}

In this study, the degree of carbonation was expressed as depth of carbonation. In accordance with the recommendations of RILEM CPC-18, [27] the depth of 
carbonation in concrete was measured. Fig. 2 shows the measurement of carbonation depth in a concrete specimen.

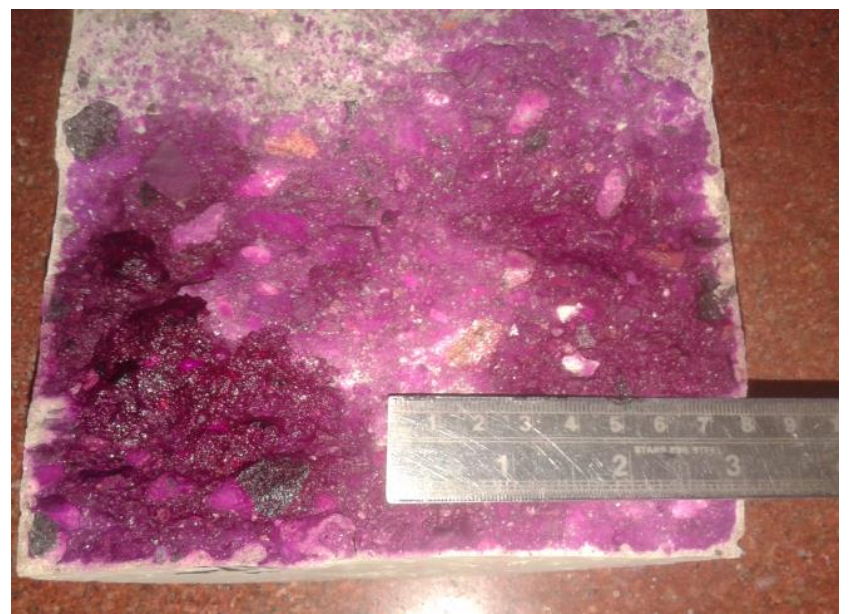

Fig.2: Measurement of carbonation depth

\section{RESULTS AND DISCUSSION}

\section{Fresh State Properties of Concrete}

Table 4 shows a decrease in slump and fresh density of concrete with an increase in the replacement levels of NCA by RCA, The reduction in slump is mainly due to the change in the nature of particle shape and surface texture of RCA in comparison to the NCA. The reduction in fresh density of concrete is mainly due to a lower specific gravity of RCA than NCA besides a relatively higher content of entrapped air because of more angular particle shape and surface texture of RCA.

\section{Hardened State Properties of Concrete}

\section{Compressive Strength}

The compressive strength developed at 7 and 28 days by concrete mixes are shown in Fig 3. The replacement of NCA by RCA decreases compressive strength of concrete mixes irrespective of testing age. It is obvious that mix M1 has developed maximum compressive strength followed by mix M2 while mix M4 has developed least strength. In mix M2 and M3, 50\% and 100\% of NCA in the size range 10-20 mm was replaced with RCA. Mix M2 shows an insignificant reduction in strength (about 5\%). However, mix M3 shows a reduction in compressive strength up to $16 \%$. Mix M4 has developed compressive strength $19 \%$ less at 7-day and $21.5 \%$ less at 28-day compared to mix M1. The result of M4 indicates that the complete replacement of natural coarse aggregate (4.75-20 $\mathrm{mm})$ by RCA causes more reduction in compressive strength than $100 \%$ replacement of natural aggregate in size range $10-20 \mathrm{~mm}$. The reduction in compressive strength is mainly attributed to the presence of micro pores and cracks in the mortar attached to RCA and also due to the presence of soft aggregate such as of brick.

\section{Flexural Strength}


28-day flexural strength developed (Fig. 4) by the concrete mixes has a similar trend to their compressive strength. Concrete mix M1 has developed the maximum flexural strength followed by M2. Mix M3 containing 100\% RCA (10$20 \mathrm{~mm}$ ) as a replacement of NCA has developed 7\% less flexural strength than mix M1. Further, mix M4 containing has developed 15\% less flexural strength than M1. It is worth to note that in-spite of the presence of few soft aggregate there was insignificant reduction in flexural strength of concrete containing RCA as a replacement of larger size of NCA i.e. $10-20 \mathrm{~mm}$. It is important to note that when the smaller size of NCA i.e. 4.75-10 mm was also replaced with RCA along with larger one, then the flexural strength was influenced more adversely than the case of larger size aggregate. The requirement of more cement paste compared to the case of larger size aggregate might be responsible for such behavior of concrete.

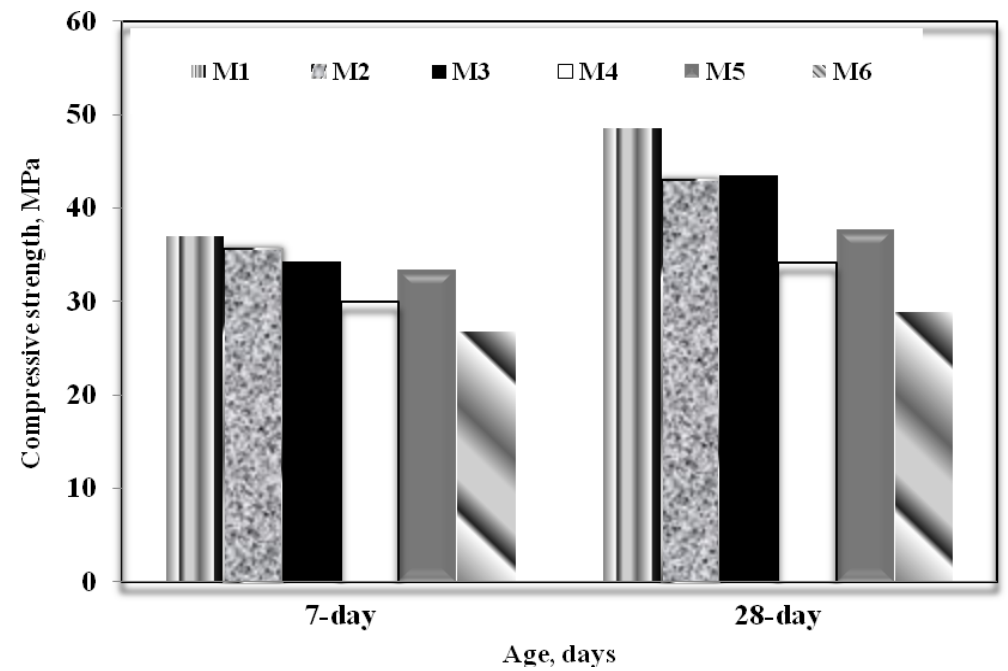

Fig.3: Compressive strength of mixes

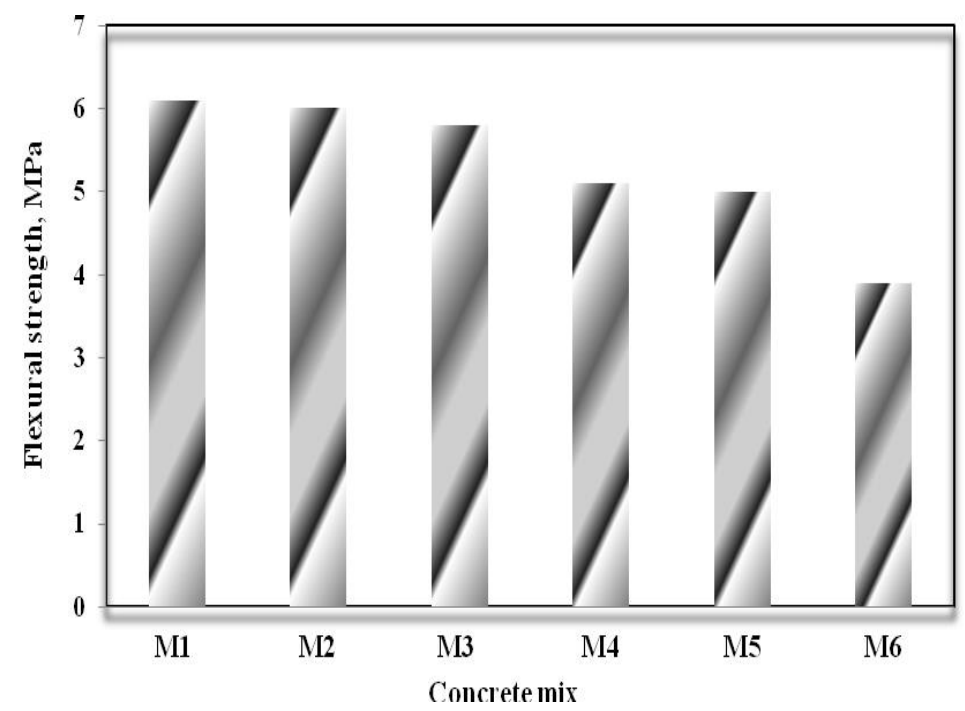

Fig.4: Flexural strength of mixes

\section{Abrasion Resistance}


The abrasion resistance test results are shown in Table 5. A lower value of abrasion loss indicates a higher resistance to abrasion of the concrete. It can be seen that there is a significant increase in mass loss representing abrasion loss due to replacement of NCA by RCA. The complete replacement of NCA decreases the abrasion resistance of concrete surface about $20 \%$. The mixes containing complete replacement of NCA with RCA in size range $4.75-20 \mathrm{~mm}$ exhibits the lowest abrasion resistance. The decrease in abrasion resistance of concrete is mainly due to comparatively inferior quality of RCA (Table 3), increase in porosity due to the presence of two transition zones, cracks and pores in mortar attached with aggregate. Over and above a lower compressive strength is also responsible for it to some extent. It is important to note that all concrete mixes used in this study can be used in pavement construction meant for pneumatic tired traffic in accordance with the guidelines of IS 9282: 1993 (Table 6).

Table 5. Abrasion resistance of concrete mixes

\begin{tabular}{lcccccc}
\hline $\begin{array}{l}\text { Abrasion } \\
\text { loss }\end{array}$ & \multicolumn{5}{c}{ Concrete mix } \\
\hline Mass & M1 & M2 & M3 & M4 & M5 & M6 \\
\cline { 2 - 6 } loss, $\%$ & 0.179 & & 0.213 & 0.22 & 0.204 & 0.24 \\
\hline
\end{tabular}

Table 6. Guidelines for different categories of concrete surfacing based on the abrasion loss of the concrete IS 9282: 1993.

\begin{tabular}{ll}
\hline Surfacing category & $\begin{array}{l}\text { Max value of abrasion loss, 5 by } \\
\text { mass }\end{array}$ \\
\hline $\begin{array}{l}\text { Concrete Pavement: } \\
\text { a) With mixed traffic including iron tyred } \\
\text { traffic }\end{array}$ & $\mathbf{0 . 1 6}$ \\
b) With pneumatic tyred traffic & 0.24 \\
\hline
\end{tabular}

\section{Drying shrinkage}

Table 7 shows the test results of the drying shrinkage of concrete mixes. The maximum value of drying shrinkage was $447 \mu \mathrm{m} / \mathrm{m}$ for mix M6. M6 has shown about 50\% more shrinkage than M5. These mixes had a w/c ratio value of 0.44 . Similar results can be seen for mixes M1 and M4 prepared at a w/c ratio of 0.38 . M4 containing RCA has a drying shrinkage value about $20 \%$ higher than the concrete containing NCA. In both the cases, the replacement of NCA by RCA has increased the drying shrinkage of concrete, which is greater for the concrete manufactured at a higher w/c ratio. A higher value of the drying shrinkage of concrete indicates that if this concrete is to be used in the construction of jointed plain concrete pavement and in jointed reinforced concrete pavement then the spacing of the construction joint needs to be reduced.

Table 7. Drying shrinkage of mixes with and without RCA

Mix Ultimate drying shrinkage, micron




\begin{tabular}{ll}
\hline M1 & 292 \\
M4 & 343 \\
M5 & 298 \\
M6 & 447 \\
\hline
\end{tabular}

\section{Carbonation of concrete}

Table 8 presents carbonation depth of the concrete mixes tested at about six months of age. It can be seen that the replacement of NCA by RCA increases the rate of carbonation of concrete. Concrete with a higher w/c ratio has a higher carbonation depth compared to concrete at a lower w/c ratio. A higher value of the carbonation depth of the concrete restricts its applications in reinforced concrete construction but does not restricts its uses in the construction of jointed plain concrete pavement and in jointed reinforced concrete pavement

Table 8. Carbonation depth of concrete mixes with and without RCA

\begin{tabular}{lc}
\hline Mix No. & Average carbonation depth, mm \\
\hline M1 & 0.9 \\
M4 & 1.1 \\
M5 & 1.2 \\
M6 & 1.5 \\
\hline
\end{tabular}

\section{CONCLUSIONS}

From the study the following important conclusions emerge:

- The replacement of NCA with RCA adversely influences the performance of concrete at the fresh and hardens states.

- Complete replacement of NCA by RCA reduces the mechanical properties of concrete. The reduction in mechanical properties of concrete depends on the extent of replacement level.

- The replacement of NCA by RCA decreases the abrasion resistance, increases the drying shrinkage and carbonation depth of concrete imposing a restriction on the use of such concrete.

- The decrease in the abrasion resistance, carbonation resistance and increase in the drying shrinkage of concrete containing RCA depends on the level of replacement of NCA with RCA. These finding is similar to earlier reported studies by several researchers [Faella et al. 2016; Thomas et al. 2013, Otsuki et al. 2003; Ann et al. 2008].

- Recycled coarser size aggregate obtained from CDW may be used to replaced NCA for the manufacturing of pavement concrete withiout affecting its abrasion resistance charcteristic beyond the limit which make it unfit for the pavement concrete with a smaller joint spacing.

\section{ACKNOWLEDGEMENTS}

The permission of the Director, CSIR-CRRI (Prof. Satish Chandra) to publish this research study is gratefully acknowledged. 


\section{REFERENCES}

Ann, K. Y., Moon, H. Y., Kim, Y. B., and Ryou, J. (2008). "Durability of recycled aggregate concrete using pozzolanic materials." Waste Manag, 28, 993999.

Buck, A. D. (1997). "Recycled concrete as a source of aggregate." ACI Mater. J, 74(5), 212-219.

Chen, K. H., Chen, H. J., and Yen, T. (2003). "Use of building rubbles as recycled aggregates." Cem Concr Res, 33(1), 125-132.

Debib, F., Courard, L., and Kenai, S. (2010). "Mechanical and durability properties of concrete of concrete using contaminated recycled aggregates." Cem Concr Res., 32(6), 421-426.

Domingo-Cabo A., Lázaro, C., López-Gayarre F., Serrano-López M. A., Serna, P., and Castaño-Tabares J., O. (2009). "Creep and shrinkage of recycled aggregate concrete." Constuc Build Mater, 23, 2545-2553.

Faella, C., Lima, C., Martinelli, E., Pepe, M., and Realfonzo, R. (2016). Mechanical and durability performance of sustainable structural concretes: An experimental study, Cem Concr Compo, 71, (1) 85-96.

I. Standard, Method of Test for Abrasion Resistance of Concrete, IS 9284, 1993.

Katz, A. (2003). "Properties of concrete made with recycled aggregate from partially hydrated old concrete." Cem Concr Res, 33, 703-711.

Knack, A. M., and Kurama, Y. C. (2013). "Design of concrete mixtures with recycled concrete aggregate." ACI Mater J, 110, 483-493.

Kou, S. and Poon, C. (2013). Long-term mechanical properties and durability properties of recycled aggregate concrete prepared with fly ash, Cem Concr Compo, 37, (1) 12-16

Kumar, R. (2017). "Influences of recycled coarse aggregate derived construction and demolition waste (CDW) on abrasion resistance of pavement concrete." Construc Build Mater, 142, 248-255.

Kumar, R., and Shekhawat, C. (2016). "Commercially available construction and demolition waste recycled coarse aggregate in the manufacture of concrete." Indian Concr J, 90, 27-35.

Levy, S. M., and Helene, P. (2004). "Durability of recycled aggregates concrete: a safe way to sustainable development." Cem Concr Res, 34, 1975-1980.

Mabin, S. M. (1993). "Recycled concrete aggregate-New York State's experience." Proceeding of the Recovery and Effective Reuse of Discarded Materials and By-Products for Construction of Highway Facilities, Denver.

Mehta, P. K. (2001). "Reducing the environmental impact of concrete." Concr Interl, ACI, 3(10), 61-66.

Naik, T. R., and Kumar, R. (2015). "Sustainable concrete with industrial and postconsumer by-product materials." Green Building with Concrete: Sustainable Design and Construction, $2^{\text {nd }}$ Edn, Edited by Gajanan M. Sabnis, Taylor \& Francis Group, New York.

Otsuki, N., Asce, M., Miyazato, S., and Yodsudjai, W. (2003). "Influence of recycled aggregate on interfacial transition zone, strength, chloride 
penetration and carbonation of concrete." ASCE J Mater Civ Eng, 15 443451.

Poon, C. S., Shui, Z. H., and Lam, L. (2004). "Effect of microstructure of ITZ on compressive strength of concrete prepared with recycled aggregates." Construc Build Mater, 18, 461-468.

Ravindrajah, R. S., \& Tam, T. C. (1985). "Properties of concrete made with crushed concrete as coarse aggregate." Magz of Concr Res,37(130),2938.

Salem, R. M., Burdette, E. G., and Jackson, N. M. (2003). "Resistance to freezing and thawing of recycled aggregate concrete." ACI Mater J, 100 (3),216230.

Tavakoli, M., and Soroushin, P. (1996). "Strength of recycled aggregate concrete made using field-demolished concrete as aggregate." ACI Mater J, 93, 182-188.

Thomas, C., Setién, J., Polanco, J.A., Alaejos, P., and Juan, M.S.D. (2013). Durability of recycled aggregate concrete, Constuc Build Mater, 40, 10541065.

Xiao, J., Li, J., and Zhang, C. (2005). "Mechanical properties of recycled aggregate concrete under uniaxial loading." Cem Concr Res, 35,11871194.

Xueqan, W., Dongxu, L., Qinghan, B., Liqun, G., and Mingshu, T. (1987). Preliminary study of a composite process in concrete manufacture, Cem Concr Res, 17(5), 709-714.

Yanik, K. (2016). "Report-global demand for aggregates to rise." http://www.pitandquarry.com/report-global-demand-for-aggregates-torise> (June, 2018). 